\title{
Artes, Pornoerotismos e Identidades IGBTQIAt em trânsitos estéticos
}

Arts, Pornoerotisms and LGBTQIA

Identities in aesthetic transits

Afonso Medeiros ${ }^{1}$

1 Bolsista Produtividade e coordenador do GP Arte, Corpo e Conhecimento (ambos do CNPq), Afonso Medeiros é Professor Titular de Estética e História da Arte da Faculdade de Artes Visuais (FAV) do Instituto de Ciências da Arte (ICA) da Universidade Federal do Pará (UFPA). 


\title{
Resumo
}

Além do puro formalismo ou estilismo iconográfico, a expressividade erótica no campo da arte pode ser vista num dialogismo entre a concepção de corpo e suas circunstâncias socioculturais. Seja sincrônica, diacrônica ou anacronicamente, qualquer análise sobre a manifestação visual da sexualidade humana se insere numa negociação (quase sempre assimétrica) entre identidades que é, ao mesmo tempo, bioestética e biopolítica. Se a arte é um campo privilegiado para a percepção de corpos e sexualidades divergentes, há que se perscrutar os modos como essas divergências tornaram-se visíveis ou invisíveis na história da arte, aqui recortada no interstício entre a modernidade e a contemporaneidade. É este o intuito primeiro deste artigo. Para tanto, a recorrência a autores tais como Lou AndreasSalomé, António Damásio, Didier Eribon, Michel Foucault, Dominique Fernandez e Judith Butler objetiva a percepção de variados matizes numa intermediação instável entre masculino e feminino que, consequentemente, nos permita vislumbrar a existência (ou não) de uma peculiar estética erótica LGBTQIA+.

\section{Palavras-Chave}

erotismo, estética, identidade, LGBTQIA+.

\begin{abstract}
Beyond the pure formalism or stylism, erotic expressiveness in the field of art must be seen in a dialogism between the conception of the body and its socio-cultural circumstances. Whether synchronous, diachronic or anachronistic, any analysis of the visual manifestation of human sexuality is part of a negotiation (almost always asymmetrical) at the same time bioaesthetic and biopolitics for the (re)construction of identities. If art is a privileged field for the perception of divergent bodies and sexualities, it is necessary to peruse the ways in which these divergences became visible or invisible in the history of art cut in the interstice between modernity and contemporaneity. This is the primary purpose of this article. Therefore, the recurrence of authors such as Lou Andreas-Salomé, António Damásio, Didier Eribon, Michel Foucault, Dominique Fernandez and Judith Butler aims at the perception of various nuances in an unstable intermediation between male and female that, consequently, allows us to glimpse the existence (or not) of a peculiar queer erotic aesthetic
\end{abstract}

\section{Keywords}

eroticism, aesthetics, identity, queer.

ISSN: 2447-1267 
Enquanto fenômeno biopsíquico, o corpo é, ao mesmo tempo, signo, objeto e interpretante. O corpo é o locus privilegiado para encontros e desencontros entre a enunciação do Eu/sujeito que enuncia o Outro/objeto e, enquanto alteridade, a enunciação do Outro/sujeito que enuncia o Eu/objeto. A identidade é sempre uma negociação sociocultural mais ou menos conflituosa entre o sentimentoentendimento de si (self) e o sentimento-entendimento que o outro constrói sobre mim. Portanto, as relações que permeiam as construções e as desconstruções dos egos e das alteridades passam sempre por semioses de subjetivação e de objetivação nas gangorras socioculturais do eu em direção ao outro e do outro em direção ao eu promovendo contínuas (auto)interpretações. Ainda mais, estes processos são variáveis e negociáveis segundo as condições de visibilidade que cada tempo e cada espaço (constituídos culturalmente) permitem para a expressão de individualidades, de alteridades e dos modos de altercação, aglutinação ou dispersão entre elas.

Como identidade, o corpo é sujeito e objeto de todas as formas de ser e estar no mundo e, por isso, ainda é o grande dilema estético, ético e lógico da humanidade. Nesse dilema estão circunscritos não somente as semioses relativas ao funcionamento psicofísico do corpo e que dizem respeito às classificações de sexo biológico (macho, fêmea ou intersexual), como também as semioses relacionadas ao funcionamento psicossocial do corpo e que dizem respeito às categorizações de gênero (masculino, feminino e transgênero). Entre as classificações do sexo biológico e as categorizações de gênero, opera a sexualidade entendida como constructo cultural que alimenta e afeta as dimensões eróticas, afetivas, espirituais, políticas e estéticas das subjetividades e objetividades dos corpos.

Em 1910, a psicanalista russo-alemã Lou Andreas-Salomé, interlocutora privilegiada de Friedrich Nietzsche, Sigmund Freud e Rainer Maria Rilke, concedeunos uma notável definição de erotismo:

\footnotetext{
"O erotismo ocupa uma posição intermédia no seio dos dois grandes grupos de sentimentos (o egoísmo e o altruísmo), ou, para falar de modo menos equívoco, de retraimento, de contração de nossa vontade individual até a separação; a hostilidade, ou a dilatação por meio da qual ele integra o Outro, o que está diante dele, como se fosse uma parte de si próprio" (AndreasSalomé, 2005, p. 87, grifos da autora).
}

Em primeiro lugar, observe-se que o erotismo para Andreas-Salomé é uma espécie de mediação entre o sentimento de si e o sentimento do outro. Em segundo lugar, essa mediação é móvel e instala um dinamismo do tipo fluxo-refluxo que vai da contração à dilatação, ou do retraimento à hostilidade quando esta "integra o Outro [...] como se fosse uma parte de si próprio". Essa hostilidade ou dilatação que internaliza o outro em si próprio, pode ser um mote para percebermos não só a expressividade do erotismo normativo (heterossexual), como também para as interpretações possíveis de erotismos divergentes da norma?

Mais de um século depois da publicação do clássico estudo sobre o erotismo da psicanalista russo-alemã, o neurocientista português António Damásio, depois de um 
diálogo profícuo com a filosofia (Descartes e Spinoza, particularmente), afirmou algo que vale a pena relacionar com a percepção de Andreas-Salomé: "A subjetividade é uma narrativa construída inexoravelmente. A narrativa surge das circunstâncias dos organismos em determinadas especificações cerebrais ao interagirem com o mundo exterior, com o mundo das memórias passadas, e com o mundo do seu interior. É esta a essência dos mistérios por trás da consciência". (Damásio, 2017, p. 221).

Configurando três formas de manifestação do mundo em nós (o exterior, o das memórias e o interior), Damásio reitera que a constituição da subjetividade se instala também em relação às circunstâncias que estão diante do sujeito, ou seja, na alteridade. Reiterando que corpo e mente não podem ser vistos separadamente, mas, ao contrário, devem ser considerados numa relação inextricável e mutuamente colaborativa, o neurocientista português indica "o self que vem da natureza e o self que vem da cultura" (Damásio, 2013, p. 275).

Os corpos naturalizados afetam os corpos culturalizados na medida mesmo em que a recíproca é verdadeira. E é nessa negociação acirrada que se constrói e se descontrói as identidades do Eu e do Outro, enquanto nessa mesma negociação o erotismo se instala como mediação e dinamismo entre fluxo e refluxo, entre contração e dilatação.

Nas sociedades ocidentais globalizadas a partir da colonialidade embutida na modernidade europeia (Mignolo, 2020) que encarou seu próprio processo civilizatório como missão inalienável de submissão linguística, científica e artística do "outro" no mundo - tratando-o como sua reserva extrativista - o corpo jamais esteve tão aparentemente liberado, tão permissivo, tão projetado, tão consumido, mas também jamais foi tão vigiado, controlado, submetido e objetificado como na atualidade.

$\mathrm{Na}$ perspectiva de um cenário intelectual euro-norte-americano do pós-guerra que cruzou algumas tendências dos estudos culturais estadunidenses (já infectados pelo estruturalismo) com os estudos pós-estruturalistas franceses, algumas tendências sociológicas focaram seus olhares nas chamadas minorias sexuais e de gênero a partir dos anos 1970. É neste veio que nasceu a Teoria Queer (nos anos 1990) para discutir os modos de (a)normalização do desejo e da sexualidade na dinâmica social, particularmente focados nos corpos desviados, subalternizados, travestidos e racializados, afrontando as concepções clássicas do pensamento moderno oriundas do cartesianismo e do iluminismo sobre subjetividade, agenciamento e identificação. Ironia das ironias, a pós-colonialidade e sua contrapartida descolonial nascem numa interlocução crítica e geohistórica (nem sempre amigável) do colonizador com o excolonizado.

Michel Foucault (1997) já expôs os modos de controle e punição dos comportamentos corporais que objetivam sua utilização, submissão, divisão, direcionamento e controle, naquilo que foi chamado pelo filósofo francês de microfísica do poder (2016), perpetrado por instituições e indivíduos de maneira difusa e sutil. Nesse sentido, as instituições (governamentais ou não) se encarregam, na atualidade, de dar continuidade ao negacionismo do corpo, o que outrora era uma tarefa dos monoteísmos e de parte da filosofia idealista. 
Antecipando-se à emergência e à repressão e comumente combatendo sua negação e sua submissão, a arte vem fazendo do corpo não só um tema privilegiado, mas sua pulsão predileta, sua matéria-prima e sua própria razão de ser. Entretanto, mesmo nos campos da arte e da cultura visual, o poder disciplinar exerce sua microfísica, sua forma rarefeita de conformar, inclusive e sobretudo na construção das identidades. Um exemplo? Basta notarmos a estética hegemônica no universo gay que impõe um corpo sarado para os bofes e um corpo curvilíneo ou andrógino para as monas.

Outra marca da modernidade capitalista é a especialização dos saberes e das experiências. A especialização no trabalho, no urbanismo, na legislação, na ciência e na arte promoveram um fatiamento dos corpos que, assim, puderam ser sutil e eficazmente controlados. Qualquer corpo despedaçado científica, artística e politicamente é um prato cheio para a agudização das ideologias e suas formas de controle. Mas, sobretudo, é nesse açougue do humano referendado pela academia que reside a mais periclitante das características da contemporaneidade ocidental urbanoide: a assimetria entre a pulsão de vida (eros) e a pulsão de morte (thanatos). Disso nos dão testemunho não só George Bataille, mas também Michel Foucault (que leu Batatille), Judith Butler (que leu Foucault) e Achille Mbembe (que leu todos), dentre muitos outros. Vivemos sim sob a égide de uma necropolítica que foi calcada numa necroestética e numa necroepistemologia inerentes à colonialidade/modernidade todas podadoras dos "excessos" do corpo erotizado e erotizante, sobretudo quando este corpo não é branco nem hetero.

A novidade (e o paradoxo) é que as nossas próprias lutas pela percepção, respeito e dignidade dos gêneros, das etnias e das sexualidades diversas e divergentes sejam subsumidas nas especialidades que comandam o sistema social da arte, da ciência e da política, ou seja, que nossas próprias formas fragmentárias de luta atendam, de alguma maneira, aos princípios controladores da microfísica do poder. Em tempo: tanto a teoria pós-estruturalista quanto a teoria de gênero mais recente, a teoria queer e a teoria decolonial ${ }^{1}$ - todas conectáveis quando o assunto é a relação entre arte, corpo e saber - têm feito um esforço notável pela diluição de fronteiras acadêmicas entre Ciências, Artes e Humanidades.

Posta de forma muito abrangente nesse cenário, a arte moderno-contemporânea não tem deixado de problematizar o corpo em suas múltiplas relações socioculturais. Entretanto, quando a representação do corpo na arte resvala na sexualidade, críticos, historiadores e teóricos, atendendo ao modo dual característico de certa pletora do pensamento ocidental, apressam-se em diferenciar essa representação do corpo como "erótica" em oposição à "pornográfica", a ponto de viger entre a crítica um cínico mantra que diz que "se é arte, não é pornografia. E se é pornografia, não é arte".

Acontece que, se considerarmos uma extensa iconografia outrora resguardada nas reservas técnicas dos museus e nas coleções privadas (invisibilizadas por séculos) 
e que vai de Giulio Romano à Márcia X, passando por Rembrandt, Courbet, Hokusai, Manet, Jean Cocteau, John Currin, Jeff Koons, Orlan, Mapplethorpe, Alair Gomes e Nan Goldin - a lista pode seguir indefinidamente -, essa dicotomia entre o erótico e o pornográfico não se sustenta, apesar dos esforços de críticos, historiadores e teóricos em circunscrever toda a representação do corpo e da sexualidade sob o conceito um tanto quanto elástico de "arte erótica" e que conta atualmente com vários museus específicos. Foi por este motivo que afirmei em outra oportunidade (2008) que para o cinismo patriarcal do mundo teórico-acadêmico da arte, o pornográfico equivaleria a uma física da sexualidade, enquanto o erótico equivaleria a uma metafísica.

E foi justamente por não conseguir defender a pornografia como provocadora de deleites estéticos típicos da arte que a fortuna crítica foi pega de calças curtas (ou arriadas) quando as milícias "da moral e dos bons costumes" atacaram a retrospectiva de Mapplethorpe nos anos 1990 ou a exposição Queermuseu em 2017 - para ficarmos apenas em dois exemplos bem notórios -, nessa tsunami de pudor hipócrita recauchutado que nos assola desde as últimas décadas do século passado, expondo o triunfo do neoliberalismo econômico e político no contexto pós movimentos contraculturais.

O ponto de vista que quero discutir hoje passa por essa questão mais geral do pornoerotismo na medida em que também tem se tornado comum uma certa visão de que uma suposta "arte ou estética gay" passaria necessariamente pela representação ou apresentação de um corpo homoafetivo extremamente erotizado e, por isso, tornou-se invisibilizado ou dissimulado na narrativa hegemônica da história da arte. Entretanto, percebemos nessa mesma fortuna crítica uma certa confusão entre afetividade e sexualidade quando se trata de relações entre indivíduos do mesmo sexo. Nesse sentido, há que se considerar a ressalva feita por Foucault, "a relação entre dois indivíduos do mesmo sexo é uma coisa. Mas gostar do mesmo sexo que o seu, ter um prazer com ele é outra coisa, é outra experiência, com seus objetos e seus valores, com a maneira de ser do sujeito e a consciência que ele tem de si mesmo" (Foucault, 2014, p. 153).

Esta afirmação de Foucault já nos permite uma gradação no enfrentamento das querelas entre erotismo versus pornografia: considerando que o erotismo é o impulso vital que permite o ir além de si mesmo (Andreas-Salomé, 2005; Bataille, 2004), toda relação entre indivíduos (homossexuais ou não) constitui uma conotação do princípio erótico. A pornografia seria, então, uma denotação do princípio erótico atualizada nas relações explicitamente sexuais entre indivíduos. E, diria, é nessa denotação possível através da expressão pornográfica que se encontra um campo fértil para a interpretação historicamente referenciada das concepções de masculino e feminino, de macho e fêmea, de ativo e passivo, de interdição e permissividade - e quem disse que a denotação pornológica é destituída de poeticidade? Nessa perspectiva, é preciso ultrapassar a visão de que a pornografia se ampara exclusivamente em clichês de perversão sexual manipulados pela indústria pornográfica - a exemplo do que 
vem fazendo os porn studies ${ }^{2}$ desde a década de 1980 - e perceber que entre essa indústria e as artes existem fluxos e refluxos dos mais diversos.

Além do mais, aquela afirmação de Foucault nos permite outra ressalva importante: a relação denotativamente erotizada entre indivíduos do mesmo sexo pressupõe objetos e valores específicos e, portanto, pode-se aduzir que tal relação é potencialmente exprimível através da arte e da sua história, fazendo-nos crer que o conjunto das expressividades dissidentes e divergentes da heteronormatividade pode, enfim, ensejar uma esteticidade singular. No entanto - repito - essa singularidade artístico-estética só adquire significado sociocultural se as duas formas de expressão e comunicação (homo e hetero) forem postas uma diante da outra na constituição da subjetividade, como afirmaram subliminarmente Andreas-Salomé e Damásio.

Em L'amour qui ose dire son nom: art et homosexualité (título que contém um trocadilho da famosa frase de Oscar Wilde), Dominique Fernandez afirma:

\begin{abstract}
"A homossexualidade masculina e feminina sempre existiu. Em todos os lugares, em todos os momentos, nós a experimentamos, a praticamos. Vamos tomar cuidado, no entanto, para que este nome genérico (forjado em 1869 e, portanto, anacrônico nos séculos anteriores) possa abranger várias formas de considerar as relações entre duas pessoas do mesmo sexo, sejam essas relações filosóficas, pedagógicas, amorosas ou sexuais - variações que dependeram de climas, de eras e de civilizações" ${ }^{3 \prime}$ (Fernandez, 2001, p. 9).
\end{abstract}

Esta afirmação de Fernandez nos chama a atenção para o cuidado com a observação dos contextos sincrônicos e diacrônicos que, no final das contas, também influem no processo de significação de qualquer expressão. Além disso, Fernandez ressoa uma outra citação de Foucault que, ao comentar o livro Homosexualité grecque (de Kenneth James Dover), assinala:

"É que os gregos, na idade clássica, mais mostraram do que disseram deles:
as pinturas de vaso são infinitamente mais explícitas do que os textos que
nos sobram - mesmo sendo de comédia. Mas, em retorno, muitas cenas
pintadas seriam mudas (e ficaram mudas até aqui) sem o recurso ao texto que
fala do seu valor amoroso. [...] O cerne da análise de Dover está aí: descobrir
o que diziam esses gestos do sexo e do prazer, gestos que acreditamos
universais (o que de mais comum, finalmente, que o gestual do amor) e
que, analisados em sua especificidade histórica, mantêm um discurso bem
singular" (Foucault, 2014, pp. 152-53).

Por enquanto, nessa conversa entre Fernandez e Foucault, basta retermos quatro aspectos: 1) as especificidades de objetos, valores e gestualidades inerentes à relação erótica entre indivíduos do mesmo sexo - o que nos permitiria perceber

2 Porn studies em inglês ou pornologie em francês: "Indiferentes às normas de bom comportamento cultural e sexual, os estudos pornográficos lançam um olhar feminista a todas as formas de representação sexual sem distinção moralista ou elitista, com particular interesse no mais 'pornográfico' e no mais obsceno' entre eles" (Vörös, 2015, p. 5; a tradução livre é nossa).

3 A tradução livre é nossa. 
códigos expressivos da homossexualidade; 2) as variedades de abordagens (filosóficas, pedagógicas, amorosas ou sexuais) que permeiam as relações homossexuais - o que nos faz perceber variações expressivas que vão da conotação (erotismo) à denotação (pornologismo) nos domínios de eros; 3) as dependências dessas variações aos contextos de épocas e de culturas, estas também variáveis nos tempos e nos espaços - o que nos permitiria desvelar as condições de visibilidade que cada momento histórico permite; 4) a necessária atenção na traduzibilidade entre discursos verbais (dizer) e discursos visuais (mostrar).

De fato, em $\bigcirc$ amor que ousa dizer seu nome, o romancista e ensaísta francês ${ }^{4}$ expõe uma extensa iconografia da homossexualidade num arco que vai da antiguidade greco-romana à contemporaneidade. Entretanto, quase toda essa iconografia referese à homossexualidade masculina, a exemplo de várias outras obras que abordam o tema. A partir daqui, já podemos nos fazer uma pergunta: Se e quando admite a expressividade homossexual, por que a história da arte ocidental é quase toda traspassada pela expressão sexual masculina? A resposta mais óbvia reside no fato de que a atividade artística tem sido, no ocidente, um privilégio de homens e, portanto, mesmo na expressividade gay que confronta o patriarcado, existe uma microfísica do poder de gênero que admite o "desvio", desde que este seja exercido pelos homens.

Esta percepção pode ser confirmada, por exemplo, na exposição Masculin: I'homme nu dans l'art de 1800 à nos jours, que aconteceu no Museu D'Orsay de 24 de setembro de 2013 a 2 de janeiro de 2014. Nela, variações sobre o nu masculino são pontuadas por obras com conteúdos homossexuais explícitos e, assim, percebemos que a expressão da homossexualidade masculina, agora privilegiada pela revisão historiográfica da arte (como vimos em Fernandez), é obra tanto de artistas homens héteros quanto de artistas homens homossexuais.

Linda Nochlin, em Por que não houve grandes mulheres artistas? (1971) nos dá vários motivos para pensar sobre a hegemonia masculina no campo da arte ao revelar que a pergunta do título de seu artigo já embute uma resposta insidiosa que escamoteia a verdadeira questão, qual seja, as condições que a sociedade ocidental negou às mulheres para que estas chegassem ao patamar do "gênio detentor de uma aura mágica" reservada exclusivamente aos homens nos domínios da história da arte. Ao demolir essa falácia, Nochlin expõe também a fragilidade dos argumentos de feministas da época que defendiam uma "arte feminina" ou uma "arte feminista" apelando para um princípio de identidade que passaria por questões como "sensibilidade", "delicadeza", "graciosidade", "instinto maternal" etc. - tudo aquilo que reitera o papel da mulher na sociedade patriarcal. Para contestar essa conexão automática entre identidade de gênero (feminino) e certo tipo de iconografia supostamente privilegiada pelas artistas mulheres, Nochlin cita artistas homens e heteros (como Raffaello Sanzio) que exprimiram em muitos de seus trabalhos uma sensibilidade que supostamente seria um ethos feminino. Seguindo a acuidade da percepção de Nochlin quanto à uma suposta "feminilidade" inerente às obras de 
artistas mulheres, poderíamos acrescentar que tal feminilidade não só já serviu de "prova" da imaginada tendência homossexual de artistas heteros (como o próprio Raffaello5), mas também nos faz pensar na presença desse ethos feminino na obra de artistas gays, a exemplo de Volver (2006) de Pedro Almodóvar.

Para os propósitos deste artigo, por enquanto basta guardarmos essa diatribe de Linda Nochlin nos seguintes termos: para pensar a hipótese da existência de uma arte ou de uma estética homossexual que se diferencie da produção artística heterossexual, é preciso considerar duas coisas: 1) as condições socioculturais de visibilidade da produção de artistas gays e lésbicas; 2) a existência ou não de formas específicas de representação da homossexualidade no campo da arte. Ressalve-se, desde já, que os artistas gays não sofreram a política de segregação e invisibilidade estética, pelo menos não tanto quanto as artistas mulheres e certamente não no período da modernidade. Se assim não fosse, não poderíamos explicar o sucesso de Leonardo, de Michelangelo, de Caravaggio e de tantos outros. Ainda que pensemos nestes casos como uma abertura à tolerância sexual, ela não se configurou como tolerância de gênero.

Judith Butler afirma que:

\begin{abstract}
"Embora os cientistas sociais se refiram ao gênero como um 'fator' ou 'dimensão' da análise, ele também é aplicado a pessoas reais como uma 'marca' de diferença biológica, linguística e/ou cultural. Nestes últimos casos, o gênero pode ser compreendido como um significado assumido por um corpo (já) diferenciado sexualmente; contudo, mesmo assim esse significado só existe em relação a outro significado oposto" (Butler, 2015, p. 31, grifos da autora).
\end{abstract}

Portanto, a caracterização do gênero passa por questões relacionais entre masculino e feminino, relações estas profundamente assimétricas nas sociedades patriarcais e que incidem na própria interpretação biológica, linguística e cultural que caracterizam as identidades. Ora, mais ou menos independentemente de como o sujeito se sente e se identifica, o poder patriarcal odeia a subversão da identidade tida exclusivamente como masculina ou feminina em termos linguísticos e culturais ou como macho ou fêmea em termos biopsicológicos e, por isso, sua microfísica está sempre preocupada em esclarecer papéis sexuais tais como ativo(a) ou passivo(a), dominador(a) ou dominado(a), bofe ou mona, tachi ou neko (no jargão japonês) etc.

A condição homossexual em si mesma já deveria pressupor o borramento de fronteiras tanto sexuais quanto sociais ligadas ao discurso de gênero. Digo "deveria" porque as coisas não são assim tão simplórias. Mas é um tanto quanto óbvio que a corporeidade de um homem afeminado, de uma mulher masculinizada, de uma trans mulher, de um trans homem, de uma drag queen, de uma travesti, de um(a) bissexual ou de um(a) intersexual - desde que assumidos enquanto tais - já constituem em si mesmos um signo indicial eminentemente corpóreo/psicológico que subverte completamente as identificações de gênero quando estas encontram-se restritas ao 
binarismo masculino-feminino. E não é demasiado lembrar que esse signo está inscrito no corpo, com o corpo e para o corpo que, por sua vez, atua de maneira sistêmica amalgamando o natural com o cultural ou rizomatizando o mundo interior com o mundo exterior e o mundo da memória. Em termos de expressividade erótica há, portanto, um entre, um meridiano elástico, uma miríade de meios tons que precisam ser considerados.

É nesse arcabouço que podemos entender uma citação de Didier Eribon retirada de seu incontornável Reflexões sobre a questão gay:

\begin{abstract}
"Mas sejam quais forem os 'papéis' que os gays adotem, seja qual for a maneira como as transformam, essas 'identidades' disponíveis têm por ponto comum estar sempre, num momento ou noutro, numa situação ou noutra, em situação instável no mundo social à sua volta. Um gay não acaba nunca com a necessidade de escolher a si mesmo diante da sociedade e do estigma. E o que Sartre chama de 'autenticidade' não pode ser compreendido a não ser como um processo jamais acabado de construção e de invenção de si" (Eribon, 2008, p. 140, grifos do autor).
\end{abstract}

As identidades disponíveis a partir dos papéis que os gays podem adotar ou transformar estão sempre numa situação de instabilidade a ser negociada social e culturalmente e essa instabilidade pode ser estendida ao universo muito mais diversificado e divergente que envolve Lésbicas, Gays, Bissexuais, Trans, Queer, Intersexuais, Assexuais e mais $(\mathrm{LGBTQ} \mid \mathrm{A}+)^{6}$. Diria mesmo que esse ser instável configura uma ontologia da condição lgbt. No quesito (re)construção da identidade do sujeito a partir de uma perspectiva erótica, insisto no dialogismo entre, por um lado, os insights de Andreas-Salomé e de Damásio e, por outro, as ideias de Dominguez, de Foucault, de Eribon e de Butler no sentido de que há um self natural e um self cultural em estado permanente de interagência, diálogo este sempre posto diante da normatividade heterossexual e visto aqui como circunstância do ser moderno-colonial que impregna a fluidez erótica no contemporâneo.

Ora, se as identidades sexuais adotáveis e/ou transformáveis perpassam a representação ou apresentação do corpo e estão sempre no fio da navalha, num lusco fusco ou numa intermitência social e assimetricamente negociável, elas serão expressáveis na e através da arte necessariamente como instabilidade no processo de invenção e reinvenção de si, do ser artista lgbt. E isso torna profundamente complexa quaisquer tentativas de perceber, verificar e categorizar na história uma arte ou uma estética dessa natureza. Em primeiro lugar, porque precisaríamos inventariar os artistas homo e transsexuais ao longo da história da arte - o que já é em si uma tarefa polêmica e hercúlea na medida em que a saída do armário nem sempre foi negociável nas sociedades ocidentais, mesmo na modernidade. Portanto, a caracterização de uma presumida identidade lgbt na arte a partir da autoria, ainda que diversificada em si mesma, só pode ser tarefa de quem tem "força na peruca".

Como já não tenho nem força e muito menos peruca, limito-me a indicar algumas 
questões que necessariamente terão que ser enfrentadas pelos agraciados com força e peruca, mas devo conjecturar que a hipótese de uma "identidade gay na arte" por enquanto é só isso mesmo: uma hipótese que, como toda hipo tese, traz em si mesma uma alta carga de falibilidade. Eu sei o quanto é tentadora esta hipótese quando relacionamos, mais ou menos anacronicamente, uma obra de um artista renascentista ou barroco com outra de Cocteau ou outra de Warhol ou outra de Mapplethorpe ou outra de Alair Gomes que, aliás, construiu relações visualmente anacrônicas sobre o corpo masculino no seio de sua própria obra fotográfica. Também temos notícias de que há pesquisadores propondo uma estética queer ${ }^{7}$ a partir da noção de experiência verificada em Walter Benjamin, em George Bataille e em Susan Buck-Morss e embora esse veio da experiência seja tão alentador quanto, creio que muitas discussões sobre a estética queer ainda não ultrapassaram os limites da performance - o que nos incitaria a testar as linhas gerais de tal estética aplicáveis a outras expressões visuais, mas não é o caso neste momento.

Aliás, muitas teorias que entraram ou surgiram no vigésimo século testaram suas potencialidades de aplicação no campo da estética. Para citar os exemplos mais pronunciados: a Semiótica (com Charles Peirce e Martine Joly), a Semiologia (com Jan Mukarovsky), o Estruturalismo (com Roland Barthes), a Escola de Frankfurt (com Theodor Adorno e Walter Benjamin), o Feminismo (com Linda Nochlin e Griselda Pollock), o Pós-estruturalismo (com Gilles Deleuze e Félix Guattari) e o Pós-modernismo (com Rosalind Krauss). Pelo visto, a busca pela aplicabilidade ou validade estética de dado sistema teórico parece ser uma tara inserida no vai e vem entre modernidade e contemporaneidade - com a Teoria Queer e com a Teoria Decolonial ${ }^{8}$ não seria diferente.

Isto posto, vejamos três modos de exposição dissonante do corpo na arte que se chocam com os valores do patriarcado ocidental, considerados os contextos de suas produções e apresentações: 1) O corpo herético; 2) O corpo pornográfico; 3) $\bigcirc$ corpo desviado.

O corpo herético só se manifesta nas culturas impregnadas pelos monoteísmos, já que na maioria das sociedades politeístas na Ásia, na África e nas Américas, erotismo e religião não são necessariamente excludentes. Assim, o corpo herético é um tipo de expressão assumidamente transgressora. Nessa categoria, podemos considerar desde A Escola de Platão ${ }^{9}$ (1900) de Jean Delville, até Atos da transfiguração - desaparição ou receita para fazer um santo ${ }^{10}$ (2015) de Antônio Obá, passando por Desenhando com terços ${ }^{11}$ (2000) de Márcia X e Ecce Homo ${ }^{12}$ (2009) de Kehinde Wiley. Com

7 "Estética Queer: experiência, subversão, multiplicidade e devir na contemporaneidade" (2015). Dissertação de Juliano Guimarães Felizardo no Mestrado em Ciências da Linguagem da Universidade do Sul de Santa Catarina (UNISUL). Disponível em: https://www.riuni.unisul.br/handle/12345/490.

8 Cf. Arte y estética en la encrucijada descolonial (vols. I e II) publicados pela Del Signo (Buenos Aires).

9 Disponível em: www.musee-orsay.fr/fr/collections/catalogue-des-oeuvres/resultat-collection.

10 Disponível em: www.premiopipa.com/2018/11/antonio-oba-expoe-criticas-sociais-ao-proximo-governofederal-para-jornal-ingles/

11 Disponível em: http://www.nonada.com.br/2017/09/artigo-museu-nao-e-playground-ou-igreja/marcia-x/

12 Disponível em: http://internationalportraitgallery.blogspot.com/2012/05/ 
exceção da obra de Delville, que envolve platonismo, cristianismo e um certo clichê de "gestualidade gay" (afeminado), todas as demais não tocam explicitamente numa corporeidade que se possa chamar categoricamente de homossexual.

Desta primeira questão posta em cena através destes quatro exemplos que envolvem significados outros que não somente o erótico, retire-se um princípio: toda exposição explícita do corpo e da sexualidade é um confronto direto ou indireto com a patriarcalidade monoteísta, mesmo que esta, como no catolicismo, não tenha padecido da iconoclastia protestante ou judaica e tenha admitido aquela profusão de nudes que Michelangelo plasmou no coração do Vaticano. Isso é particularmente visível na escultura Virgem das Mercês ${ }^{13}$ (2015, de Elisabet Stienstra) exposta em meio a muitas iconografias de Maria na exposição Mary (Museum Catharijneconvent, Utrecht, 10 de fevereiro a 20 de agosto de 2017).

O corpo pornoerótico se manifesta em obras que quebram com a dicotomia erotismo-pornografia. São signos explícitos das sexualidades que chocam simplesmente porque a manifestação plena do desejo sexual que deveria ser da ordem do privado se torna pública e visível. É o caso de A Origem do mundo ${ }^{14}$ (1866) de Gustave Courbet, A Origem da guerra ${ }^{15}$ (1989) de Orlan, Man in Polyester Suit ${ }^{16}$ (1980) de Robert Mapplethorpe e Rotterdam ${ }^{17}$ (2006) de John Currin. Neste tipo de expressão verifica-se um foco nos órgãos sexuais que na tradição artística desde o Renascimento deveriam estar devidamente dissimulados. Várias dessas imagens, por mais que já estejam musealizadas e que seus autores sejam celebrados no circuito das artes, são das mais censuradas nas redes sociais, o que atesta a sobrevivência da pudicícia do patriarcado ocidental em pleno século XXI.

O corpo desviado é o tipo de pornoerotismo mais visado pelas mentes conservadoras, dado que se refere a sexualidades vistas como divergentes do padrão homem-mulher ou masculino-feminino. Como exemplo, basta citar O Sono ${ }^{18}$ (1866) de Gustave Courbet, David et Jonathan ${ }^{19}$ (2005) de Pierre et Gilles e Lewis and Matt on the Bed, Cambridge, MA $^{20}$ (1988) de Nan Goldin. Note-se que em nenhum desses exemplos o foco está nos órgãos genitais ou na relação sexual, mas a denotação homoerótica faz com que tais exemplos sejam considerados "desviantes", embora não necessariamente pornográficos ou heréticos.

O primeiro tipo (corpo herético) borra as fronteiras entre sagrado e profano. $\bigcirc$ segundo tipo (corpo pornoerótico) borra as fronteiras entre erótico e pornográfico. $\bigcirc$ terceiro tipo (corpo desviado) borra as fronteiras entre masculino e feminino. Embora cada uma das imagens citadas ofereça potencialidades de leituras e interpretações

13 Disponível em: https://br.pinterest.com/lauroborges/elisabet-stienstra/

14 Disponível em: www.musee-orsay.fr/fr/collections/catalogue-des-oeuvres/resultat-collection.html

15 Disponível em: http://www.photo.fr/exposition/l-homme-tombe-la-veste-a-la-galerie-pierre-alain-challier

16 Disponível em: www.artbasel.com/catalog/artwork/46163/Robert-Mapplethorpe-Man-in-Polyester-Suit

17 Disponível em: http://warburg.chaa-unicamp.com.br/obras/view/3663

18 Disponível em: www.reddit.com/r/LePetitMusee/comments/hxmg1w/le_sommeil_gustave_courbet

19 Disponível em: artistalphabet.files.wordpress.com/2013/03/gilles_pg_davidetjonathan_2005_300.jpg

20 Disponível em: https://museemagazine.com/culture/2018/11/14/exhibition-review-nan-goldin 
muito além da expressão da sensualidade corporificada, tocando em questões como racialização, etnocentrismo etc., elas também servem para algumas premissas instáveis na verificação daquela hipótese de uma "expressividade lgbt", considerando autorias e contextos: 1) Nem todo monoteísmo consegue transcender a carnalidade erótica; 2) Nem todo nu masculino (ou feminino) delícia é obra de artista lgbt que não saiu do armário; 3) Nem toda obra de conteúdo homoerótico e/ou homoafetivo é obra de artista lgbt. Assim, devemos considerar que uma iconografia erótica que toca particularmente nos processos de fruição de uma parte da comunidade lgbt pode transcender os limites das intenções estéticas homossexuais e pode tocar uma infinidade de sensibilidades, homossexuais ou não. Em outras palavras, o que se poderia chamar de "expressividade estética" do erotismo homo, bi, inter ou transexual se insere entre uma feitura com intenções lgbt e uma leitura com intenções lgbt, isto é, numa semiose impregnada pelos contextos que envolvem a autoria da obra e sua recepção.

Estas últimas conclusões desdobram a questão anterior no sentido de que uma estética visual de caráter lgbt expressa uma sensibilidade (não necessariamente gay, ou lésbica, ou bissexual ou transexual ou queer em termos autorais) extravasada particularmente entre a modernidade (Courbet) e a contemporaneidade (Goldin). Em outros termos, essa sensibilidade lgbt não exclusivamente lgbt, parece ser um dos motes estéticos de nossa própria contemporaneidade, muito bem explorada, por exemplo, na Exposição Queermuseum (2017) - sensibilidade esta que parece presidir também certas revisões historiográficas da arte, como vimos anteriormente

Os três tipos gerais aqui expostos sucintamente são suficientemente óbvios, mas seus exemplos nos levam exatamente ao " $X$ " da questão que ora proponho: Partindo do fato de que o nu e a erótica masculina e o nu e a erótica feminina na história da arte estão bem determinados e de algum modo atendem à classificação binária de gêneros que a sociedade patriarcal tornou hegemônica, cabem as seguintes perguntas: 1) Que tipo de coisa diferiria a "estética hetero" da "estética homo" em termos de representação ou apresentação do corpo e da sexualidade? 2) A partir dessa diferenciação (pressupondo que ela seja possível), que caminhos de pesquisa seguir para a categorização ampla de uma "arte ou estética gay"? Desdobrando esta questão, teríamos duas outras: 2.1) Criando argumentos sobre uma suposta visualidade lgbt que ultrapasse este universo e se espraia por obras de artistas homens e mulheres heterossexuais? 2.2) Ou defendendo a ideia de que a estética lgbt (seja ela qual for) é aquela plasmada exclusivamente nas obras de artistas lgbts? E, por fim: 3) Visto que o corpo não tem sido um tema menor na história da arte, a sexualidade lgbt expressa na arte também se envolve nas querelas entre o erótico e o pornográfico, isto é, entre o permissível e o interdito? E se envolve, é possível borrar historicamente as fronteiras entre erotismo e pornografia?

A partir dessas premissas instáveis, talvez a hipótese de uma expressão estética peculiar ao universo homo, bi, trans e intersexual esteja por demais desfocada e, assim, tenha que ser calibrada nos seguintes termos: como se (re)constrói as identidades eros-estéticas dos corpos divergentes da heteronormatividade? Trata-se, portanto, 
de trocar o "qual" pelo "como".

Em todo o caso, não podemos nos esquecer nunca que nos encontramos naquela situação de instabilidade das identidades (da qual nos falava Didier Eribon) e num contexto sociocultural no qual o "gênero pode ser compreendido como um significado assumido por um corpo (já) diferenciado sexualmente", segundo Judith Butler.

O que quero dizer com tudo isso? Quero insinuar que nosso próprio modo lgbt de lidar com as instabilidades identitárias nos obriga a abrir os olhos para as instabilidades históricas e estéticas no trato com qualquer indício de "expressividade lgbt", seja esta qual for. Percorrendo a própria historiografia hegemônica da arte (em grande parte escrita por homens brancos), percebemos que nem todo historiador, crítico, teórico ou professor de arte esteve (ou está) disposto a enfrentar as instabilidades estéticas em consonância com as instabilidades históricas e sociais das definições de gênero e das relações entre estes numa sociedade ainda dividida em classes.

Só poderemos, portanto, encarar a contribuição de um sentimento LGBTQIA+ no campo da arte através da expressividade pornoerótica, se assumirmos as complexidades das nuances identitárias que definem nosso modo de ser e estar no mundo.

\section{Referências}

BATAILLE, Georges. O erotismo: ensaio. São Paulo: Arx, 2004.

BUTLER, Judith. Problemas de gênero: feminismo e subversão da identidade. Rio de Janeiro: Civilização Brasileira, 2015.

DAMÁSIO, António. O sentimento de si. Lisboa: Círculo de Leitores, 2013.

DAMÁSIO, António. A estranha ordem das coisas: a vida, os sentimentos e as culturas humanas. Lisboa: Círculo de Leitores, 2017.

ERIBON, Didier. Reflexões sobre a questão gay. Rio de Janeiro: Companhia de Freud, 2008.

FERNANDEZ, Dominique. L'amour que ose dire son nom : art et homosexualité. Paris: Éditions Stock, 2001.

FOUCAULT, Michel. Vigiar e punir: nascimento da prisão. Petrópolis: Ed. Vozes, 1997.

FOUCAULT, Michel. Genealogia da Ética: subjetividade e sexualidade. Rio de Janeiro: Forense Universitária, 2014.

FOUCAULT, Michel. Microfísica do poder. Rio de Janeiro; São Paulo: Paz e Terra, 2016.

GÓMEZ, Pedro Pablo. Arte y estética en la encrucijada descolonial II. Buenos Aires: Del Signo, 2014. 
MEDEIROS, Afonso. O imaginário do corpo entre o erótico e o obsceno: fronteiras líquidas da pornografia. Goiânia: Funape, 2008.

MIGNOLO, Walter. Histórias locais / projetos globais: Colonialidade, saberes subalternos e pensamento liminar. Belo Horizonte: Editora UFMG, 2020.

MUSEU D'ORSAY (org.). Masculin: L'homme nu dans l'art de 1800 à nos jours. Paris: Flammarion, 2013 (catálogo da exposição homônima).

NOCHLIN, Linda. Why have there been no great women artists? (1971). In: REILLY, Maura (ed.). Women artists: the Linda Nochlin reader. London: Thames \& Hudson, 2015, pp. 42-68.

VÖRÖS, Florian (dir.) Cultures pornographiques: anthologie des porn studies. Paris : Éditions Amsterdam, 2015. 